\title{
INDUSTRIAL HOSPITALS.
}

BY

\section{R. A. BOLAM, M.D., M.R.C.P., AND R. ORDE, B.A., PHYSICIAN, SKIN DEPARTMENT, HOUSE GOVERNOR,} ROYAL VICTORIA INFIRMARY, NEWCASTLE-UPON-TYNE.

The character of the British hospital of the future will be largely determined by the first steps taken to make use of the hospital beds at present vacant in Poor Law insti. tutions. That use must be nrade of these beds, or a portion of them, almost at once is generally agreed. Patients cannot much longer be allowed to lie untreated in their homes, often within a stone's throw of admirable hospital accommodation.

At first sight the problem would appear to be one as easy of solution as was that which confronted the country on the outbreals of war. Buildings were then comman. deered, staffs appointed, and in a surprisingly short time hospitals for the treatment of sick and wounded soldiers established in every town. Indeed, the problem might be thought to be an easier one, since suitable buildings are now standing ready for use, while the number of sick to be dealt with is perhaps as one to ten, or even to twenty. The difference, however, between these two problems is fundamental. In warfare cost cannot be counted-victory is everything - but victory once gained there follows a period of financial sickuess. At this moment the country is financially sick and the limit of bearable taxation has been reached. Cost is therefore one of the controlling factors in the prob'em of how to make use of the Poor Law accommodation.

Again, warfare breaks only for the period of hostilities the ingrained habits of peace. It may alter, it may develop institutions, but if those institutions are in consonance with the genius of the people and are grounded in their affections, then warfare need not destroy. There are no institutions more typical of our race, more firmly established in the affections of the great mass of our people, than the voluntary hospitals. Any step taken that would tend to injure permanently their usefulness could result only in taking from us something we really like and giving us something we do not really want.

Cost and the voluntary hospital, therefore, cannot be left out of consideration in solving our problem. They are the two main controlling factors. Keeping, then, in view that we have patients to be treated, that we have accommodation for the purpose, that cost is of paramount importance, and that the voluntary hospitals must be preserved, we propose to examine the suggestion that the Poor Law hospitals should be utilized without delay as general hospitals.

Before doing so, however, we think it desirable to consider shortly certain aspects of the voluntary hospitalstheir patients and their sources of support. A patient in a voluntary hospital pays nothing for his treatment; he may contribute towards the cost if he wishes; there is, in the main, no compulsion, nothing of the nature of a tax. It is true that a gradual change is taking place; but, in order not to confuse the issue, it is better to regard him as a patient who costs the State nothing and who contributes if he does contribute, of his own free will. It is true also of the untreated patient, whether his name appears on the waiting list of a general hospital or not, that he expects if he secures admission to have nothing to pay. Now, a large number of these are industrial patients, some wholly incapacitated by accident or disease, some able to follow their employment intermittently, some able to work continually but requiring treatment of one form or another to render them capable of full effort. What the volume of these may be it is difficult to assume. Probably we are not far out in regarding one-third of the patients in a general hospital, and a rather larger proportion of those on the waiting list, as industrial. For the purpose we have in view we limit the term industrial to those patients who can be definitely associated with some organization economically interested in their speedy return to work. At the present time the voluntary hos. pitals have difficulty in finding money to carry on. In their search for support they are being compelled to modify their purely charitable constitution. In taking stock of their situation they have found that they are being made use of by a large number of patients able to contribute materially towards the cost of treatment. They find also that prosperous mining companies, large insurance organizations, city corporations, and employers of labour generally rely upon them to treat their sick and injured. One of the most striking instances of this is to be seen in the attitude of city corporations towards the hospitals within their boundaries. Street accidents have always been received and treated without delay. Now it is taken as a matter of course that the voluntary hospitals should provide instant and efficient treatment for all injured in fires, in railway disasters, in coliisions in the street, in brawls, in riots, by acts of violence and of crime. It is expected that charity should do this work free of cost. The knowledge gained by this stock-taking lias opened the eyes of the committees of the voluntary hospitals to the fact that they are being taken advantage of; that there is an attempt to place on the shoulders of charity a burden charity was never meant to bear-a burden which it can no longer bear. In certain districts realization of this fact has resulted in a very considerable increase in support derived both from workmen them. selves and from their employers. But this support is still quasi-voluntary. City corporations, speaking generally, do little in this direction; insurance companies do nothing at all.

Now there are three methods by which money can be raised, and three only:

(A) By voluntary gifts.

(B) By taxation, governmental or local.

(C) By payment (on the basis of work done) from employers, employees, private persons.

So far as the last method is concerned it is immaterial whether payment is made direct or through some form of insurance so long as the insurance does not take the form of State insurance, in which case it becomes in part, or in whole, a form of taxation, and should be considered as such.

If we examine the income account of a voluntary hos. pital-wo take the one with which we are most intimately acquainted-we find it can be divided up roughly as follows :

(1) Voluntary gifts

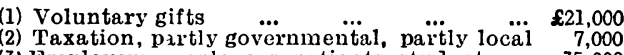

(3) Emplion, party governmental, partly local 7,000

$$
\text { Total } \quad . . \quad \ldots \quad \ldots \overline{£ 63,000}
$$

Note.-We have left out of consideration payments made for the treatment of soldiers and pensioners.

With regard to (1) there is no need to commen't furthex than to say that it is made up of annual subscriptions, donations, voluntary collections of various kinds, and amounts to one-third of the total.

In this particular instance the sum under (2) happens to be almost entirely for the treatment of venereal diseases, and as such differs in a certain sense from taxation for general hospital purposes. The taxation is for the purpose of providing a protection against a real and terrible danger and is comparable to taxation levied, say, for police purposes. In any case it affects neitler favourably nor adversely the principle of voluntary contributions. The work for which it is paid is one which does not engage the sympathies of the public. The voluntary hospital undertakes the task because it may be in a position to do it better and less expensively than any other organization, and it is also of scientific interest. In other hospitals the amount raised under the heading taxation may bear a rather higher proportion than one-ninth of the total, but it is probable that in none of the large ones does it amount to as much as one-seventh.

Division (3) is the important one - it is fre-ninths of the total. It is hardly possible to regard it yet as coming wholly under the heading, "payment on the basis of work done." The employers' contributions are still tinged with the idea of charity. Some of them may be wholly charitable, as, for instance, in the case of an em. ployer of labour making a grant in excess of the cost of treatment of patients coming from his works. Again, many such contributions, even when they in no way cover the cost of treatment, are regarded by the employer as purely charitable because he has not yet realized that the restora. tion of his workmen to health at the earliest possible moment saves his pocket. In essence, however, they are contributions in return for which something is given, 
whether the gift is realized or not, and as such a payment pure and simple under the heading (C).

The contributions from employees resemble those from employers in the main. Ostensibly they are a voluntary levy for the purpose of helping the unfortunate; in reality they have come to be subscriptions, more or less in adequate, to a benefit club. The contributors expect to receive treatment should they fall ill. These contribu. tions have not yet by any means reached the stage of bearing a definite relationship to the cost of work done, but they are tending to do so in certain districts, and appeals made to bodies of workmen now show the number and cost of treatment of patients coming from their works or from their area.

Such are the sources of income of the voluntary hospitals. From what has been said it will be seen that we have hospitals still bearing the name "voluntary," still enjoying the confidence and affection of the people because of that name and of the spirit that animates them, and yet drawing only one-third of their support from truly voluntary sources. It cannot, then, be contended that to retain the voluntary spirit it is necessary to trust wholly to charitable sources of support. The conclusion we draw, therefore, is that, as in the great voluntary hospitals a large proportion of the support is given on the basis of work done, so, if there is to be no destructive rivalry between voluntary effort and the State, it is to this source of support that the Poor Law must first look for money; if, that is, we are prepared to admit, as we must admit, that to attempt to run two classes of hospitals-the voluntary and the Poor Law, the latter being supported entirely out of funds derived from taxation--will inevitably result in the disappearance of the former.

It will be agreed that the most urgent need of the country at the moment is the re-establishment of industry. Obviously, then, we should turn our attention first to that part of hospital treatment that tends to make the industrial worker a more efficient workman. As we have already said, a large proportion of patients in hospitals are engaged in industry. In many cases they are patients because of their work. In others they are a clog on industry because, through ill health, they are industrially inefficient. Any step taken, then, to cure them must benefit industry as a whole. If, then, the Poor Law accommodation is first used for this purpose it will be helping directly towards providing the necessary money for wider and more ambitious schemes of health. Enly a country industrially prosperous can afford elaborate health schemes.

Suppose we set apart in the Poor Law hospitals sufficient accommodation to deal with the general hospital industrial patients we shall relieve the pressure on the roluntary hospital and treat those on their waiting lists who, while not medically or surgically urgent in the hospital sense, are yet industrially urgent. By doing so we may be laying the foundation of great industrial hospitals. Let us take a sample case, that of a large industrial area served by two comparatively large voluntary hospitals, one of which has a medical school, and by several Poor Law institutions with accommodation suitable for general hospital purposes. Each of the voluntary hospitals deals with a large number of industrial patients and each has a waiting list on which are the names of many more. Consideration of the list of one hospital alone shows roughly a total of 1,500 suppliants for admission. Of these, over 400 arvait operation for hernia, and 150 for conditions such as haen 0 rhoids. The majority of these are workers. Three weeks, on the average, in hospital, followed by a brief holiday, would return them to the ranks as efficient workmen. In this area we have reason to believe that 200 beds would not only treat the industrial waiting list patients but would treat also at least a third of the industrial patients at present in the wards of the voluntary hospitals. The relief thus given would enable voluntary hospitals to admit many of the non-industrial patients at present on their waiting lists. Such accommodation could readily be found in one of the Poor Law hospitals. We do not suggest that 200 beds would satisfy the present hospital situation, but we do suggest that it would deal with a definite class of hospital patients the responsibility for the treatment of which may fairly be laid on shoulders other than those of the State.

Let us look at this from another point of view. On the waiting list of a voluntary hospital is the name of a miner suffering from a complaint which incapacitates him from hewing coal. There his name may remain for weeks, months, in certain cases for more than a year. Is it con. ceivable that in these days when output means so much the mine manager's will allow such a man to remain one day longer untreated when they know that for $£ 10$ they can, in three weeks' time, have his disability removed? Four months' absence from work and on the waiting list means the loss of the labour which hews nearly 100 tons of coal. The matter may be looked at from many other points of view. For example, the value of this man as indicated by his wages-the economic balance is still in favour of immediate treatment; or, again, from the com. pensation point of view (if a compensation case), treat. ment beats compensation in the financial contest. We present this case to the employer, not as a lesson in ethics, but as a lesson in his own sphere-economics The lesson is true whatever the length of the un. necessary waiting may be. It is only a matter of degree. The lesson is equally true in principle in the case of the intermittent worker, or in the case of a constant but inefficient worker-inefficient through ill health.

We lay no stress whatever on an estimate of beds required for an area. There are no completely reliable figures, but if more beds are required, then there are more beds to be had. We do suggest, however, that a comparatively small number of beds will relieve the present pressure in a very remarkable way. We submit that this industrial line is the easiest and the least controversial method of initiating the Poor Law institutions in their new rôle of general hospitals.

So far, then, we have accommodation; we have suggested the class of patients to be admitted, and we have suggested a source from which money may be expected. We do not suggest that the whole cost should come out of the pockets of the employers; on the contrary, we are of opinion that it is of the utmost value in the building up of character that the workmen should themselves con tribute towards their own cure. Evidence is not wanting that the workers are willing to contribute pound for pound with their employers to such an end. There are many employees, too, who feel that they have neither the desire nor the right to claim eithe full or partial assist. ance from their employers, and who are ready-nay, anxious-to find such a sum as $£ 10$ if only they might be restored to full working capacity thereby. The lines upon which this can be done are given us in the example of the voluntary hospital mentioned abore, the only difference being that in the industrial beds payment would be guaranteed before admission.

There remains now staff and method of control. We suggest that at first there should be close co-operation between the industrial hospital and the voluntary, that members of the staff of the voluntary hospital should give part of their services to the industrial. In every large voluntary hospital there are assistant surgeons and sur. gical registrars who are either fully trained in work of this character, or who in their training are daily in the closest touch with those who set the standard of surgical work in the district. It is important that the industrial hospitals should secure the confidence of the workmen and of their employers from the outset. This confidence can most easily be gained by employing members of voluntary hospital staffs to do the work. As time goes on the industrial hospital will no doubt grow more and more independent, but even when fully established there is everything to be gained by friendly ties with the voluntary hospitals and the medical schools.

For an industrial hospital of 200 beds a staff of four-part-time surgeons, two resident medical officers, and occasional specialist assistance is all that is necessary. Such a staff could deal with the operative work of such a hospital, in which the length of stay would average three weeks. Assuming the ordinary rate of occupation, there would be about 60 admissions per week and if these were all patients requiring operation and each of the four surgeons gave two days a week, the daily list would not be beyond their powers.

The services of these officers would have to be remunerated. Assuming that the cost per patient in an industrial hospital is as much as the cost in the voluntary hospitals-namely, $110-$ the addition of $20 \mathrm{~s}$ to this amount would provicle a sump a turnover of 3,000 patients per year more timan sufticient to pay each a salary of $£ 500$; the addition of 40 s. would pay $£ 1,000$ each.

As a matter of fact, it is probable that the cost per patient in the industrial would be less than in the volun. tary hospital, and that the figure $£ 10$ would be sufficient 
to cover the cost of payment of staff on the smaller scale. The industrial hospital would escape many charges which the voluntary, due to its elaborate departments and equip. ment, has to meet.

We have seen the suggestion that the Poor Law hospitals should be handed over to voluntary committees. It is difficult to imagine any practicable method of attaining this end. We submit, however, that it might be possible in each area to ereate an industrial body which, while in no way assuming the functions of administrative control, might yet bo expected to interest itself in matters of vital importance to the well-being of the worker. It is in every way to be desired that both employers of labour and their workmen should realize that output and efficiency depend as much upon health as they do upon accurate bookkeeping, accurate costing, energetic salesmanship, and the like. An Area Committee representative of employers, workmen, chambers of commerce, insurance. companies, and so on, specially charged with the survey of the means of treatment of the industrial sick and disabled within their area, might serve a useful function without in any way interfering with any. organization which already exists or which it may be in the mind of the Ministry of Health to establish for the control of the Poor Law hospitals.

If it be asked how are the beds to be acquired, the answer is clear. They cannot be claimed or compelled, but if the Poor Law Guardians offer the beds, they can be used provisionally. So long as there remain, or are elsewhere provided, sufficient beds to satisfy the demands of the sick poor, the guardians may, if they will, utilize those vacant in the manner indicated. We are well aware that in certain districts already Poor Law beds have been offered and accepted for the purpose of relieving pressure on the voluntary hospital with gratifying results. The practical difficulties encountered in coming to a working arrangement have been:

1. The selection of the class of patient to be treated.

2. The awkwardness of treating the same type of patient on different terms in the voluntary hospital and in the Poor Law beds.

Both these difficulties appear to be surmounted by the scheme outlined.

Admission and discharge to hospital would be through the medical superintendent, just as through the resident medical officer in many large hospitals. Since the medical superintendent must be held by the guardians to be responsible, he would be nominally supervisor of the whole staff and its work. Given goodwill and tact, there is no reason why such arrangements should not speedily and successfully be entered into.

By way of summary, we submit that the proposition advanced offers an immediate partial solution of hospital difficulties, a solution which does not injure existing voluntary institutions or prejudice the proper development of larger schemes of utilizing Poor Law beds. It predicates the establishment of industrial wards, or even industrial hospitals, to deal with (1) workers incapacitated by industry; (2) workers unable through curable disabilities to do full work. Its adoption would be of profound economic adrantage by clearing the waiting lists of industrial patients, and would open up the tran. sition of the Poor Law beds to general hospital uses-

(a) Without cost to rates or taxes.

(b) With the co-operation of employers and employed.

(c) Without arousing opposition from the voluntary hospitals.

It demands beds relatively few in comparison with the number actually vacant. It could be carried on equally well by the present Poor Law authorities, or by other local authorities to whom the beds or institutions might be temporarily or permanently transferred.

Finally, no stioma can attach to any patient who pays for what he gets; and no adverse criticisin can be sustained against treatment carried out by a staff substantially the same as that of the voluntary hospital.

OWing to the impossibility of obtaining foreign litera. ture, the publication of the Zentralblatt für Physiologie will be suspended at the end of the current year.

\section{THE CARE OF PHYSICALLY DEFECTIVE CHILDREN.}

A JoINT conference of the Invalid Children's Aid Association and the Central Committee for the Care of Cripples was opened on November 16th at the Guildhall. Sir William Bennett, chairman of the Invalid Children's Aid Association, presided at the morning session, and in the absence of the President of the Board of Education, the opening address was delivered by Mr. J. Herbert Lewis, M.P., Parliamentary Secretary to the Board.

Mr. Lewis expressed the sense of the community's gratitude for the work done by the voluntary associations for child welfare, especially in the linking together of local educational authorities and hospitals for the purpose of securing treatment for those needing it. Lest the children, when cured of their physical ailments, should find themselves without the intellectual equipment necessary to maintain themselves, it was essential, he said, that education should go hand-in-hand with remedial treatment. During the past twenty years 123 day schools, accommo. dating 9,000 of these children, and 12 residential schools, providing for 540, had been established. Early recognition and early treatment of these cases were dependent on information supplied by health visitors, infant welfare centres, voluntary associations, hospitals, and general practitioners. A large increase would be required in the numbers of orthopaedic surgeons, nurses, and teachers available for prevention and treatment of crippling ailments. With proper treatment 75 per cent. of child cripples could be turned into satisfactory workers; money thus expended was a sound investment.

Mrs. 'TOWNSEND, of the Invalid Children's Aid Associa. tion, urged the need of combination and co-ordination in the work of the State, the local authorities, and the voluntary agencies. The Association had thirty-six affliated societies, and the children dealt with annually by it had increased from 584 in 1888 to over 33,000 during 1919. There was still need for much greater provision of residential accommodation and educational facilities for invalid children. The conference adopted a resolution that:

The time has come when a national inquiry should be made into the nature and extent of crippling among children, with a view to its prevention and remedial treatment.

At the evening session, at which Sir ARTHUR STANLEY presided, Dr. JAMES WHEATLEY described the orthopaedic scheme in operation in Shropshire :

The scheme consisted of three parts-the hospital itself, arrangements for after-care, and a body of health visitors. The equipment of such a hospital was expensive, and therefore the establishment should not be too small; a hospital of from 200 to 250 beds seemed to be the ideal. For the purposes of aftercare fourteen centres had been started in the country, and these centres were also used as places where prelifniuary examinations could take place before admission to hospital. The most important consideration of all was the organization of an efficient body of health visitors, upon whom it depended whether orthopaedic cases were taken up in the early stages when they could be readily cured.

On the motion of Dr. Fraser, deputy medical officer for Cumberland, a resolution was passed expressing the opinion :

That the age at which grants are available for the treatment of cripples should be extended to the maximum age for continuation classes under the Education Act, 1918.

Sir RoBERT JoNES, Chairman of the Central Committee for the Care of Cripples, presided at the morning session held on November 17th. Mr. H. S. PLATr, in the course of a paper describing the work done in America, said that few general hospitals in that country* were without a special department for the treatment of crippled children; the work, as a general rule, was still founded on the co-operation of voluntary organizations. Dr. J. ANDERSON SMITH described the treatment of heart cases at the Edgar Lee Home.

At the evening sitting, at which Sir NAPIER BURNETT, presided, Sir RoBERT JoNEs said that, roughly speals ing, half the deformities were due to tuberculosis and rickets, and the rest were congenital or due to poliomyelitis, but there was hardly a crippled child, hovever distorted, who could not be improved sufficiently to male him a valuable industrial asset. In most of the deformitins of children there was a stase when, to the uninitiated, recovery seemed complete and all parental anxiety was allayed; this was often the most critical moment in treatment, and was a period which should be provided for ir any Government scheme. From his observation of the results achieved in various hospitals, Sir Robert Jones 